OPEN ACCESS

Edited by: Cristina Santin,

Swansea University, United Kingdom

Reviewed by:

Yamina Pressler,

Colorado State University,

United States

Stefan Doerr,

Swansea University, United Kingdom

*Correspondence:

Gustavo Saiz

g.saiz@imperial.ac.uk

${ }^{\dagger}$ Present Address:

Gustavo Saiz,

Department of Life Sciences, Imperial

College London, Ascot, United Kingdom

Specialty section:

This article was submitted to

Biogeoscience,

a section of the journal

Frontiers in Earth Science

Received: 03 July 2017 Accepted: 29 December 2017

Published: 12 January 2018

Citation:

Saiz G, Goodrick I, Wurster C Nelson PN, Wynn J and Bird M (2018) Preferential Production and Transport of Grass-Derived Pyrogenic Carbon in NE-Australian Savanna Ecosystems.

Front. Earth Sci. 5:115.

doi: 10.3389/feart.2017.00115

\section{Preferential Production and Transport of Grass-Derived Pyrogenic Carbon in NE-Australian Savanna Ecosystems}

\author{
Gustavo Saiz ${ }^{1 * t}$, Iain Goodrick ${ }^{1}$, Christopher Wurster ${ }^{1,2}$, Paul N. Nelson ${ }^{1}$, Jonathan Wynn ${ }^{3}$ \\ and Michael Bird ${ }^{1,2}$ \\ ${ }^{1}$ Centre for Tropical Environmental and Sustainability Science, College of Science and Engineering, James Cook University, \\ Cairns, QLD, Australia, ${ }^{2}$ ARC Centre of Excellence for Australian Biodiversity and Heritage, James Cook University, Cairns, \\ QLD, Australia, ${ }^{3}$ School of Geosciences, University of South Florida, Tampa, FL, United States
}

Understanding the main factors driving fire regimes in grasslands and savannas is critical to better manage their biodiversity and functions. Moreover, improving our knowledge on pyrogenic carbon (PyC) dynamics, including formation, transport and deposition, is fundamental to better understand a significant slow-cycling component of the global carbon cycle, particularly as these ecosystems account for a substantial proportion of the area globally burnt. However, a thorough assessment of past fire regimes in grass-dominated ecosystems is problematic due to challenges in interpreting the charcoal record of sediments. It is therefore critical to adopt appropriate sampling and analytical methods to allow the acquisition of reliable data and information on savanna fire dynamics. This study uses hydrogen pyrolysis (HyPy) to quantify PyC abundance and stable isotope composition $\left(\delta^{13} \mathrm{C}\right)$ in recent sediments across 38 micro-catchments covering a wide range of mixed $\mathrm{C}_{3} / \mathrm{C}_{4}$ vegetation in north Queensland, Australia. We exploited the contrasting $\delta^{13} \mathrm{C}$ values of grasses (i.e., $\mathrm{C}_{4} ; \delta^{13} \mathrm{C}>-15 \%$ ) and woody vegetation (i.e., $\mathrm{C}_{3} ; \delta^{13} \mathrm{C}<-24 \%$ ) to assess the preferential production and transport of grass-derived PyC in savanna ecosystems. Analyses were conducted on bulk and size-fractionated samples to determine the fractions into which PyC preferentially accumulates. Our data show that the $\delta^{13} \mathrm{C}$ value of $\mathrm{PyC}$ in the sediments is decoupled from the $\delta^{13} \mathrm{C}$ value of total organic carbon, which suggests that a significant component of PyC may be derived from incomplete grass combustion, even when the proportion of $\mathrm{C}_{4}$ grass biomass in the catchment was relatively small. Furthermore, we conducted 16 experimental burns that indicate that there is a comminution of PyC produced in-situ to smaller particles, which facilitates the transport of this material, potentially affecting its preservation potential. Savanna fires preferentially burn the grass understory rather than large trees, leading to a bias toward the finer $\mathrm{C}_{4}$-derived $\mathrm{PyC}$ in the sedimentary record. This in turn, provides further evidence for the preferential production and transport of $\mathrm{C}_{4}$-derived $\mathrm{PyC}$ in mixed ecosystems where grass and woody vegetation coexist. Moreover, our isotopic approach provides independent validation of findings derived from conventional charcoal counting techniques concerning the appropriateness of adopting a relatively small particle size threshold (i.e., $\sim 50 \mu \mathrm{m}$ ) to reconstruct savanna fire regimes 
using sedimentary records. This work allows for a more nuanced understanding of the savanna isotope disequilibrium effect, which has significant implications for global ${ }^{13} \mathrm{C}$ isotopic disequilibria calculations and for the interpretation of $\delta^{13} \mathrm{C}$ values of PyC preserved in sedimentary records.

Keywords: carbon isotopes, savanna, biomass burning, black carbon, pyrogenic carbon, charcoal, hydrogen pyrolysis

\section{INTRODUCTION}

Fires are common in many ecosystems, but are particularly ubiquitous in seasonally dry savannas and grasslands, which comprise more than $80 \%$ of the area globally burnt (Giglio et al., 2013). However, a decreasing trend in global area being burnt has been reported over the past 18 years, which appears to be significant in grass-dominated ecosystems (Andela et al., 2017). Understanding past fire regimes and the main factors driving fire dynamics is important to better manage biodiversity and ecosystem functions (Conedera et al., 2009; Santín and Doerr, 2016). It is equally relevant to improve our knowledge of recent pyrogenic carbon ( $\mathrm{PyC})$ dynamics, including the provision of accurate information on $\mathrm{PyC}$ formation, transport and deposition, which is fundamental to better understand a significant slow-cycling component of the global carbon cycle (Bird et al., 2015).

Sediment charcoal records of small lakes have been extensively exploited to reconstruct fire histories across a range of ecosystems (Patterson et al., 1987; Millspaugh and Whitlock, 1995; Duffin et al., 2008; Leys et al., 2017). However, a disproportionate number of studies have focused on forested ecosystems despite the spatial significance and higher fire frequency of ecosystems where grasses either dominate (e.g., grasslands) or co-exist with woody vegetation (e.g., savannas) (Leys et al., 2015). The assessment of past fire regimes using charcoal peaks in the sedimentary record is particularly problematic in grassdominated ecosystems due to the relatively high frequency of fire events, which makes very difficult to detect individual fire episodes (Leys et al., 2017). Other challenges associated with the interpretation of the charcoal record in sediments range from the lack of a standardized methodology for preparation, quantification and identification of samples, to resolution constraints inherent to the method used (i.e., the degree of temporal, spatial, and event resolution that sedimentary charcoal can offer) (Patterson et al., 1987; Conedera et al., 2009). It is therefore critical to adopt appropriate sampling and analytical methods to allow for the acquisition of reliable data and information on ecosystem fire dynamics (Conedera et al., 2009).

Research exploiting the sedimentary terrestrial record to reconstruct past fire regimes has typically investigated a number of physical characteristics of charcoal such as particle counts, size distribution, and morphotype analyses (Patterson et al., 1987; Clark, 1988; Duffin et al., 2008; Crawford and Belcher, 2014; Leys et al., 2015, 2017). For example, the size of source areas for micro- and macroscopic charcoal have been assessed through charcoal counts of different size classes in surface sediment samples collected across 17 savanna water bodies in Kruger National Park, South Africa (Duffin et al., 2008). This study showed that fire intensity, proximity, and area are unequally reflected in the charcoal record of tropical savannas, and concluded that the relevant source area for charcoal in lakes was between 0 and $5 \mathrm{~km}$ for pyrogenic particles $>50 \mu \mathrm{m}$. Other research has further confirmed that charcoal count in mixed fuel source landscapes is a function of local area burned (Leys et al., 2015), and subsequent work recommends the adoption of a small particle size thresholds (i.e., $60 \mu \mathrm{m}$ ) in ecosystems having a significant presence of grass biomass due to the relatively small size and easily comminuted nature of grass-derived $\mathrm{PyC}$ (Leys et al., 2017). The importance of discriminating between herbaceous and woody derived charcoal in sediment records is a research priority, since it could significantly improve the assessment of the temporal variability of fuel types in charcoalbased reconstructions of past fire regimes (Marlon et al., 2016).

The assessment of particle size distribution may also be significant in ecological studies investigating PyC dynamics as micro- and macroscopic charcoal may have different preservation potentials (Kuhlbusch et al., 1996; Thevenon et al., 2010; Mastrolonardo et al., 2017). Saiz et al. (2015a) conducted 16 experimental fires across a broad range of savannas in NE Australia, and showed that $<10 \%$ of the total PyC produced by biomass burning in those ecosystems is emitted into the atmosphere as particles capable of moving far from the site of production, while a much larger proportion remains (initially) close to the site of production. PyC remaining on the ground may subsequently be re-mineralised by biotic and/or abiotic processes, be re-combusted in subsequent fire events, be exported in dissolved or particulate form, and/or accumulate in the soil or in the sedimentary record (Bird et al., 2015).

Previous work recommends the discrete analyses of contrasting particle sizes to gain deeper insights in charcoal taphonomy, especially if combined with independent validation of the pyrogenic origin of the particles (Thevenon et al., 2003; Conedera et al., 2009). In this context, the carbon isotope composition of $\mathrm{PyC}$ is amenable for use in fire reconstructions, particularly in savanna environments, as it represents one of the main tracers capable of providing a fingerprint of the type of vegetation being burnt (Bird et al., 2015). Indeed, the contrasting $\delta^{13} \mathrm{C}$ values of tropical grasses, which primarily use the $\mathrm{C}_{4}$ photosynthetic pathway $\left(\delta^{13} \mathrm{C}>-15 \%\right)$, and woody vegetation, all having the $C_{3}$ photosynthetic pathway $\left(\delta^{13} \mathrm{C}\right.$ $<-24 \%$ ) allow for a discrete differentiation of the precursor biomass in studies assessing $\mathrm{PyC}$ in mixed $\mathrm{C}_{3} / \mathrm{C}_{4}$ ecosystems (Saiz et al., 2015a). There are however, potential complications limiting the interpretation of the isotopic signal, which includes isotopic fractionation effects associated with the production of 
PyC during combustion. Saiz et al. (2015a) have demonstrated that savanna fires produce $\mathrm{PyC}$ that is relatively ${ }^{13} \mathrm{C}$ depleted (up to $7 \%$ ) with respect to the precursor biomass. This has been referred to as the savanna isotope disequilibrium effect (SIDE), which is a concept that explains the difference in $\delta^{13} \mathrm{C}$ between the precursor vegetation and $\mathrm{PyC}$ compounds produced during the combustion of biomass. Other factors precluding a straightforward interpretation of isotopic results are the physical fractionation of $\mathrm{PyC}$ particles derived from $\mathrm{C}_{3}$ vs. $\mathrm{C}_{4}$ sources as a result of the preferential combustion of grass biomass, and potentially differing transport efficiencies of PyC (Bird and Gröcke, 1997; Saiz et al., 2015a).

While there has been some recent progress in our current understanding of PyC produced during tropical savanna fires (Saiz et al., 2015a), there remains limited information available on its dispersal pathways. Therefore, in the present study we use hydrogen pyrolysis ( $\mathrm{HyPy}$ ) and carbon isotopic analyses to investigate the relationship between ecosystem $\delta^{13} \mathrm{C}$ and the $\delta^{13} \mathrm{C}$ of PyC derived from burning of those ecosystems in recent sedimentary records across a broad range of tropical savannas in NE Australia. The HyPy methodology consistently isolates highly condensed (stable) carbon components (HyPyC or SPACsee methods) that are pyrogenic in origin, from complex organic and sedimentary matrices (Wurster et al., 2012, 2013; Cotrufo et al., 2016). This material corresponds to the most recalcitrant component of the PyC spectrum, and can be used for the purposes of $\mathrm{PyC}$ quantification and isotope analyses. Despite being a relatively novel technique, there is already abundant literature demonstrating that $\mathrm{HyPy}$ satisfactorily isolates $\mathrm{PyC}$ in aromatic clusters (with a ring size $>7$ ) from other organic carbon (OC) across a wide range of environmental matrices (e.g., Meredith et al., 2012; Wurster et al., 2012, 2013; Saiz et al., 2015a; Cotrufo et al., 2016). Meredith et al. (2012) observed a lower PyC abundance for grass char using HyPy than with other analytical methods (i.e., CTO-375 and $\mathrm{NaClO}$ ), and inferred that the latter techniques reflected carbon trapped within silica phytoliths in the grass char, which also suggests that phytolith occluded carbon was effectively removed by HyPy. Therefore, even if the potential bias that phytoliths might exert on the $\delta^{13} \mathrm{C}$ of $\mathrm{HyPyC}$ has not yet been specifically assessed, we believe that such influence may be limited.

Our first hypothesis (H1) proposes that the relative contribution of $\mathrm{PyC}$ to total organic carbon (TOC) in sediment samples is higher in grass-dominated ecosystems than in more wooded savannas as a result of both the higher incidence of fires (Furley et al., 2008), and the production of proportionally more recalcitrant $\mathrm{PyC}(\mathrm{HyPyC})$ per unit of total carbon exposed (TCE; this term includes all carbon from biomass, necromass, and ground litter). Saiz et al. (2015a) showed that the latter is the result of the incomplete combustion resultant from fast-moving fires characteristic of grass-dominated savannas. This does not mean that the combustion woody vegetation does not produce large amounts of $\mathrm{PyC}$, quite the contrary. However, the difference lies in the fact that, while most of TCE in grass-dominated fires does get combusted, or at least thermally altered, most of the carbon stored in woodier ecosystems is commonly unaffected by fire (i.e., tree stems). Moreover, the sustained high temperatures of these fires may promote a more complete combustion of the fuels, and thus, the production of proportionally lower amounts of highly recalcitrant $\mathrm{PyC}(\mathrm{HyPyC})$ compared to grassdominated savannas. We also hypothesize $(\mathrm{H} 2)$ that fine material produced during the combustion of grass-derived biomass will be preferentially exported from the site of production and this will be reflected to some degree in its preferential accumulation in the sedimentary record. In addition to assessing the sedimentary record across a broad range of mixed $\mathrm{C}_{3} / \mathrm{C}_{4}$ ecosystems, we analyzed surface material collected immediately after experimental fires and compared results against neighboring locations left unburnt. The aim of this component of the study was to provide an estimate of the evolution of TOC and PyC abundance in different size fractions of material remaining on the ground following a fire to further test for differential transport efficiencies between $\mathrm{PyC}$ derived from grass and woody biomass sources.

The objectives of this study were therefore to: (i) assess the variation of $\mathrm{PyC}$ abundance in recently deposited sediments across a broad range of tropical savannas (Objective 1); (ii) evaluate the preferential combustion of grass biomass and factors affecting the isotopic composition of PyC (Objective 2); (iii) assess the potentially superior transport efficiency of grassderived PyC (Objective 3); and (iv) use the isotopic approach to validate the establishment of a particle size threshold that is optimal for conducting fire research in tropical savannas (Objective 4). The latter having been advocated by previous research employing charcoal counting techniques to study past fire regimes in savanna environments (e.g., Duffin et al., 2008; Leys et al., 2017).

\section{MATERIALS AND METHODS Field Sampling Methodology \\ Sediment Sampling}

This study was conducted along a 500-km transect in Queensland (Australia) between May and September 2011. Figure 1 shows the sampling location and the distribution of green perennial vegetation in northeast Australia, which represents a proxy for the relative proportion of woody vegetation (e.g., trees and shrubs) in total vegetation. The contrasting climate across the sampling locations had a strong influence on both the species and structural composition of the local ecosystems. As such, there was a noticeable trend to both higher total biomass and relative contribution of woody $\left(\mathrm{C}_{3}\right)$ vegetation to the total biomass as rainfall increases from $\mathrm{SW}$ to $\mathrm{NE}$ (Figure 1). The vegetation transect spanned humid savanna woodlands to comparatively dry Mitchell grasslands characterized by $>95 \% \mathrm{C}_{4}$ grass biomass (Saiz et al., 2015a). Tree canopy cover ranged from $<5 \%$ for a site established in a heavily dominated grassland ecosystem at the SW end of the transect (Mitchell grassland) to $50 \%$ for a woodland savanna occurring $\sim 80 \mathrm{~km}$ away from the coast at the NE end of the transect (Saiz et al., 2015a). The vegetation present at all studied sites comprised a grass layer beneath varying densities of Eucalyptus and Acacia species, which reached up to $25 \mathrm{~m}$ tall at the humid end of the transect (Torello-Raventos et al., 2013). The 


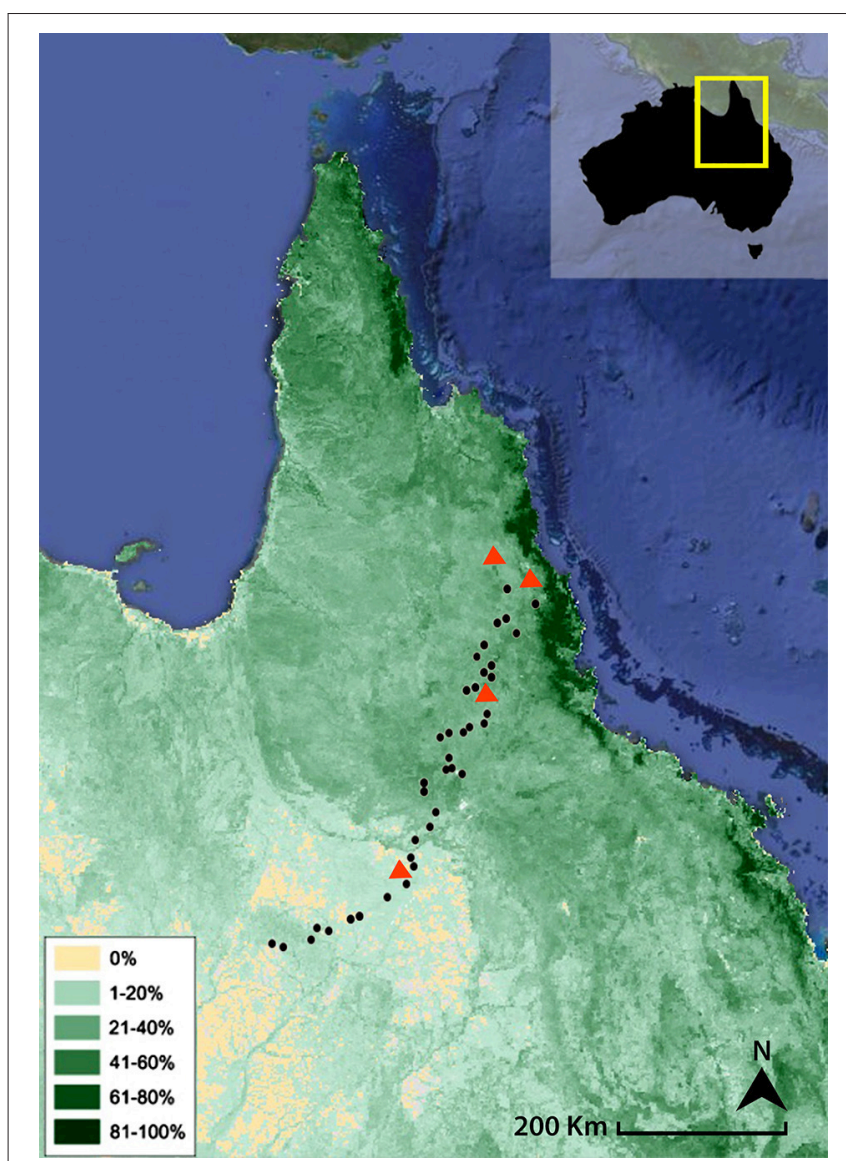

FIGURE 1 | Map showing the relative distribution (\%) of green perennial vegetation in northeast Australia. Land cover data is derived from VegMachine ${ }^{\circledR}$ CSIRO (Karfs et al., 2004). Dots represent the farm dams on which superficial sediment was sampled, while triangles denote the locations of the experimental burns.

most abundant grass species were Themeda australis, Imperata cylindrica and Heteropogon contortus.

Surficial sediment was collected from 38 micro-catchments (farm dams) encompassing a wide variety of savanna ecosystems along the transect. Farm dams are purposely-built, small-scale water reservoirs established for agricultural purposes (e.g., cattle drinking and small-scale irrigation; Supplementary Figure 1), and are relatively common across NE Queensland. Sampled dams extended from relatively humid environments near the northeast coast $\left(21^{\circ} \mathrm{S}-143^{\circ} \mathrm{E}\right.$; MAP $\left.=1,650 \mathrm{~mm}\right)$ to the much drier inner regions $\left(17^{\circ} \mathrm{S}-145^{\circ} \mathrm{E} ; \mathrm{MAP}=435 \mathrm{~mm}\right)$ (Figure 1). Sampled dams were typically smaller than $100 \mathrm{~m}$ in diameter, with catchments generally extending $<1 \mathrm{~km}$. A wide climatic range was chosen to provide the experiment with the broadest possible range of woody vs. grass biomass proportions in order to enable the establishment of broad patterns in the abundance and isotopic composition of $\mathrm{PyC}$ from recent sedimentary records.

We used a purposely-made extensible collector to retrieve surficial sediment (top $5 \mathrm{~mm}$ ) from submerged locations as far away as possible from the shore. The sediment sample collected at each dam was a composite of three sampling locations. Sampling distances typically ranged from 15 to $20 \mathrm{~m}$ from the shore. Sampling was restricted to dams showing little or no evidence of algal or macrophyte presence in order to minimize the potentially confounding influence of autochthonous vegetation in our results. However, it is clear that the influence of autochthonous vegetation on TOC cannot be entirely dismissed on the basis of their visual absence, thus we established a relationship between the stable carbon isotope composition of sediment samples and: (i) the proportion of vegetation remaining green throughout the year (perennial biomass photosynthetically active); (ii) the relative reduction in green vegetation between the wet and the dry seasons at each micro-basin, in order to identify samples exhibiting significant deviations from the general trend (Figure 2). These relationships were explored to provide additional confidence that any potential impact of algal and/or macrophyte carbon on the $\delta^{13} \mathrm{C}$ values of TOC was minimal. As such, strong individual deviations from robust relationships could then be singled out as potentially having a strong influence of autochthonous vegetation, and thus be confidently excluded from further data interpretation.

\section{Sampling of Surface Material in Burned and Unburned Quadrats}

We sampled surface (vacuumed) material at four sites along the transect to obtain information about ground OC dynamics as impacted by fire (Figure 1). The sampling procedure has been described in detail in Saiz et al. (2015a), and we only provide a brief description here. Four small-scale $\left(1 \mathrm{~m}^{2}\right)$ burning experiments were carried out at each of the four sites selected ( $n$ $=16$ ). The experimental setup was designed to ensure capture of all particulates remaining on the ground immediately after the fire (burnt quadrats). Fires took place within a metallic structure fitted with leaning side panels that were lowered after the flames self-extinguished to minimize the lateral export of burnt material. After the unit had cooled, remaining stubble within the enclosed burn was cut at ground level and the quadrat was subsequently vacuumed with a DC 23 Motorhead vacuum cleaner (Dyson Appliances Ltd., NSW, Australia). This operation was systematically carried out by the same user across all burning experiments and over the same length of time to allow for intercomparison of results. Vacuuming is unable to systematically retrieve the characteristically highly heterogeneous coarse woody debris, and it was therefore not included in this sampling. The vacuumed material was stored in separate labeled containers. Vacuuming may potentially disrupt the true distribution of size aggregates, which may be particularly significant in the case of very brittle, recently burnt grass biomass. However, we suggest that such experimental bias may be of relatively minor importance in this context if one considers that such fragile material gets rapidly comminuted in the environment by wind and rainfall anyway, and that the smallest fraction $(<10 \mu \mathrm{m})$ represents on average less than $4 \%$ of the total mass vacuumed (data not shown).

Additionally, the same vacuum procedure was used on two adjacent $1 \mathrm{~m}^{2}$ biomass quadrats $(16 \times 2 ; n=32)$ to determine TOC and PyC present on the soil surface prior to burning (a surrogate for the evolution of $\mathrm{PyC}$ abundance since a previous 


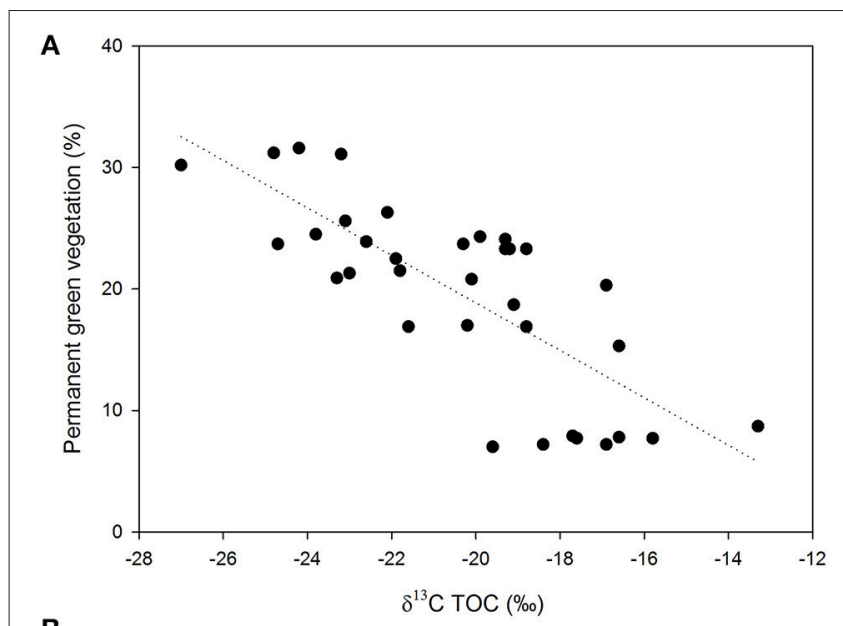

B

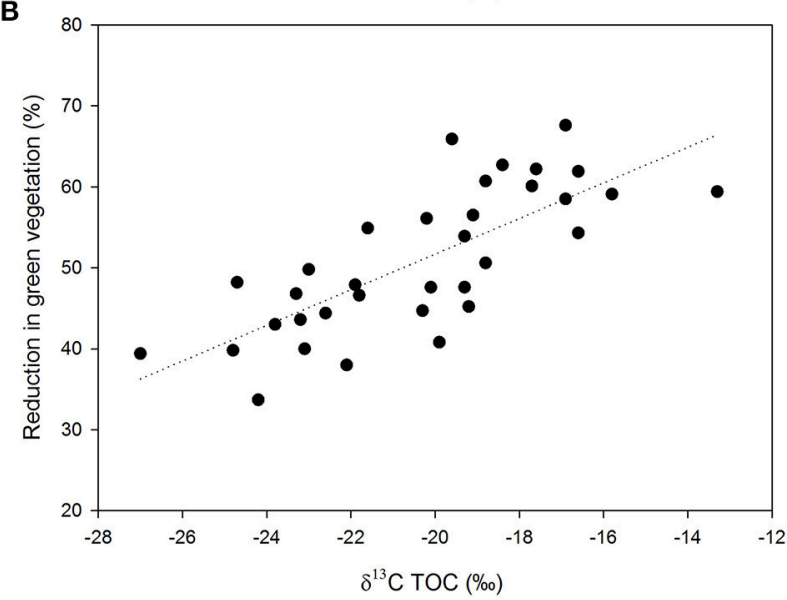

FIGURE 2 | (A) Relationship between the stable carbon isotope composition of sediment samples and the proportion of vegetation remaining green throughout the year (perennial biomass photosynthetically active) at each micro-basin; (B) Relationship between the stable carbon isotope composition of sediment samples and the relative reduction in green vegetation between the wet and the dry seasons. Regression coefficients $\left(r^{2}\right)$ are 0.60 and 62 for $(\mathbf{A}, \mathbf{B})$ respectively; $p<0.05$ in both regressions. Land cover data is derived from VegMachine ${ }^{\circledR}$ (Karfs et al., 2004), a software tool that summarizes decades of Landsat satellite imagery processed and compiled by the Remote Sensing Centre, Queensland Department of Science, Information Technology and Innovation (Australia).

fire at the site). The purpose was to broadly assess the evolution of surface C (both TOC and PyC) on locations unaffected by fire for longer than 2 years. We refer to these plots as "unburnt" to distinguish them from the burnt quadrats. Before vacuuming, all the aboveground biomass was harvested and separately quantified. This sampling procedure was carried out in duplicate at each burning location, thus resulting in a total of $8 \times$ $1 \mathrm{~m}^{2}$ vegetation quadrats sampled per studied site. This provides an estimate of initial TOC and PyC abundance before the fire, which could serve as reference to compare against burnt quadrats in order to obtain information about the carbon distribution dynamics of different size fractions (i.e., $<10,10-125$, and $>125 \mu \mathrm{m}$ ). Upon collection, all samples were individually stored inside labeled plastic containers.

\section{Laboratory Methods Sample Preparation}

On arrival at the laboratory, samples were dried at $60^{\circ} \mathrm{C}$ for 5 days before being weighed and sieved to $2 \mathrm{~mm}$. Samples were subsequently size fractionated by wet sieving at 125 and $10 \mu \mathrm{m}$ to conform with the definition of microcharcoal (10$125 \mu \mathrm{m})$ (Haberle, 2005). This procedure thereby also enables the discrete analysis of very fine $<10 \mu \mathrm{m}$ PyC, which is relevant as it is likely to be a major component of aerosol $\mathrm{PyC}$ (Andreae and Merlet, 2001). Bulk samples and the resultant fractions were then freeze-dried, weighed and finely milled prior to further analyses. Visually distinct coarse textured sediment samples were purposely tagged to help with the interpretation of their potentially distinct behaviors, as values of coarse textured samples may be strongly influenced by the inherently low physicochemical protection they offer against decomposition.

\section{Hydrogen Pyrolysis}

The HyPy technique has been shown to perform satisfactorily in characterizing $\mathrm{PyC}$ abundance in a range of environmental matrices (Meredith et al., 2012). The method separates PyC in aromatic clusters having with a ring size $>7$ from other OC. This component is usually referred to as $\mathrm{HyPyC}$ or as stable polycyclic aromatic carbon (SPAC), and represents PyC that is likely to be resistant to environmental degradation. Therefore, HyPy effectively isolates a component that is distinct in isotopic composition from the TOC of the sample. In the present work, and for the sake of simplicity, we use the term PyC to generically refer to the most recalcitrant component of $\mathrm{PyC}$ isolated by $\mathrm{HyPy}$, and equivalent to both $\mathrm{HyPyC}$ and SPAC.

HyPy has been described detailedly in a number of publications (e.g., Meredith et al., 2012; Wurster et al., 2012, 2013). In short, samples are loaded with a Molybdenum catalyst ( $\sim 10 \%$ of dry weight) by means of an aqueous/methanol solution of ammonium dioxydithiomolybdate $\left[\left(\mathrm{NH}_{4}\right)_{2} \mathrm{MoO}_{2} \mathrm{~S}_{2}\right]$. Dried, catalyst-loaded samples are then placed in a reactor to be pressurized at 150 bar $\mathrm{H}_{2}$ under a sweep gas flow of $5 \mathrm{~L} \mathrm{~min}^{-1}$, heated at $300^{\circ} \mathrm{C} \mathrm{min}^{-1}$ to $250^{\circ} \mathrm{C}$, then stepped at $8^{\circ} \mathrm{C} \mathrm{min}^{-1}$ to a final hold $\mathrm{T}$ of $550^{\circ} \mathrm{C}$ for $2 \mathrm{~min}$. There is a need to account for the mass loss of the loaded catalyst during HyPy. Therefore, the abundance of carbon in the sample after HyPy is determined relative to TOC (initial mass of carbon after treatment/the mass of carbon loaded) and reported as the relative contribution of $\mathrm{PyC} / \mathrm{TOC}$ or PyC/Sample (\% or $\mathrm{mg} \mathrm{g}^{-1}$ units).

\section{Carbon Abundance and Isotope Composition}

The carbon abundance and stable isotopic composition $\left(\delta^{13} \mathrm{C}\right)$ of samples were determined using a Costech Elemental Analyzer (EA) fitted with a zero-blank auto-sampler coupled via a ConFloIV to a ThermoFinnigan DeltaV ${ }^{\text {PLUS }}$ mass spectrometer using Continuous-Flow Isotope Ratio Mass Spectrometry (EA-IRMS). Analyses were conducted at James Cook University's Cairns Analytical Unit. Stable isotope results are reported as per mil (\%o) deviations from the VPDB reference standard scale for $\delta^{13} \mathrm{C}$ values. Precisions (S.D.) on internal standards for elemental carbon abundance and stable carbon 
isotopic composition were better than $\pm 0.08 \%$ and $\pm 0.2 \%$ o respectively.

\section{Statistical Methods}

Data for any measured variable were tested for normal distribution by Kolmogorov-Smirnov tests, and where necessary data were log- transformed. Regression analyses were conducted for estimating the relationships among the variables of interest. All reported regressions were significant at $P<0.05$ level. Specific regressions using bulk samples include all sites $(n=38)$ unless specifically stated. Analyses of covariance (ANCOVA) were performed to test for significant differences between regressions obtained between $\delta^{13} \mathrm{C}$ values of bulk sediment samples and differences in $\delta^{13} \mathrm{C}$ between the PyC component and the TOC pool for different size fractions. The ANCOVA test is shown in Supplementary Table 1. One-way ANOVA with Tukey HSD post hoc comparison was performed to test for significant differences in $\delta^{13} \mathrm{C}$ values and comparable relative contributions of PyC to TOC between the different size fractions. All statistical analyses were carried out with SPSS 17.0 (SPSS Inc. Chicago, IL, USA).

\section{RESULTS}

\section{Variation in $\delta^{13} \mathrm{C}$ Values and Carbon Contents in Surface Sediments of Farm \\ Dams}

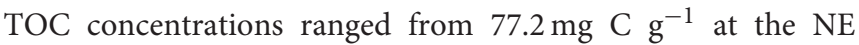
(higher precipitation) end of the transect to $2.1 \mathrm{mg} \mathrm{C} \mathrm{g}^{-1}$ observed in a very coarse-textured sample (Figure $3 \mathbf{A}$ ). $\delta^{13} \mathrm{C}$ values of TOC ranged from $-13.3 \%$ in grass-dominated environments in the interior to $-28.1 \%$ observed in closedcanopy woodlands occurring near the coast. There was a negative correlation between $\delta^{13} \mathrm{C}$ of bulk sediments and TOC abundance (Figure 3A; $r^{2} 0.40 ; p<0.05$ ). Similarly, there was a negative correlation between $\delta^{13} \mathrm{C}$ values of bulk sediments and PyC contents (Figure 3B; $r^{2} 0.37 ; p<0.05$ ). The absolute concentration of $\mathrm{PyC}$ showed a gradual decrease toward the drier southwestern end of the transect similar to the trend observed in TOC contents. However, the relative contribution of PyC to TOC was lower in the wetter more heavily wooded savannas, and showed a steady increase toward the drier, grass-dominated ecosystems to the SW (Figure 3C; $r^{2} 0.15 ; p<0.05$ ).

Samples with low TOC concentrations had a greater relative contribution of PyC (Figure 4). Very coarse-textured samples $(n=5)$ showed much greater relative contributions of $\mathrm{PyC}$ relative to their TOC concentration regardless of their $\delta^{13} \mathrm{C}$ values (Figure 3C). This proportion reached a maximum of 39\%, and was relatively uniform in samples with TOC contents greater than $25 \mathrm{mg} \mathrm{C} \mathrm{g}^{-1}$ (with values ranging from 2 to $10 \%$; Figure 4; $\left.r^{2} 0.74 ; p<0.05\right)$.

Figure 5 shows the differences in $\delta^{13} \mathrm{C}$ values between TOC and $\mathrm{PyC}$ along the transect. The $\delta^{13} \mathrm{C}$ value of $\mathrm{PyC}$ in the sediments is decoupled from the $\delta^{13} \mathrm{C}$ value of TOC, suggesting that HyPy effectively isolates a component that is distinct in isotopic composition from TOC. Differences were greater (up to

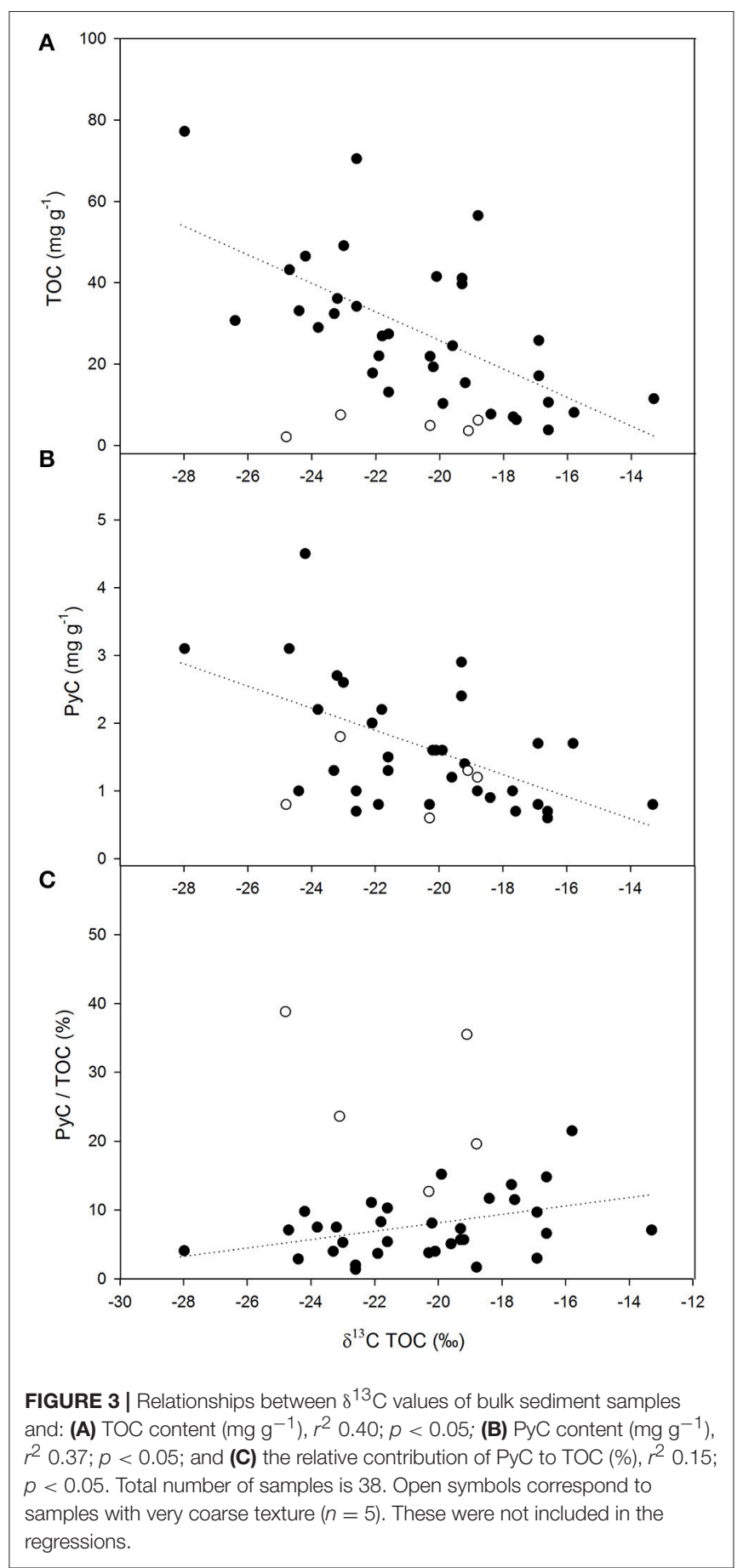

$7 \%$ ) in more heavily wooded savanna where the $\mathrm{PyC}$ component generally showed less negative $\delta^{13} \mathrm{C}$ values compared to the TOC in the same sample. These variations were smaller, and occasionally reversed, both in grass-dominated ecosystems and in the very coarse textured samples (Figure 5). Small or negative differences in $\delta^{13} \mathrm{C}$ values were associated with greater relative contributions of PyC to TOC (Figure 6).

The separate analysis of the different size fractions revealed large differences in $\delta^{13} \mathrm{C}$ values between the TOC and $\mathrm{PyC}$ 


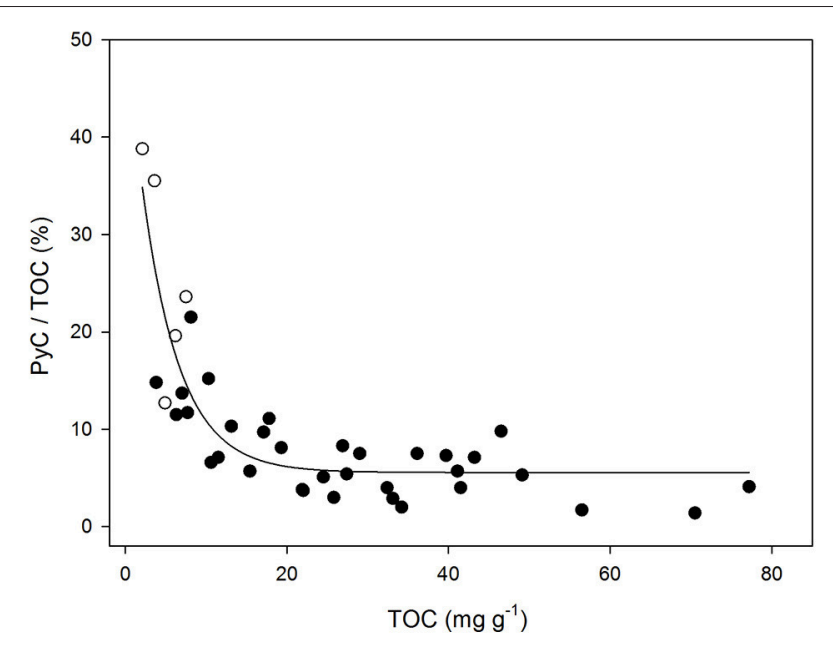

FIGURE 4 | Relationship between TOC content ( $\mathrm{mg} \mathrm{g}^{-1}$ ) of bulk sediment samples and the relative contribution of PyC to TOC (\%); $r^{2} 0.74 ; p<0.05$. Open symbols correspond to samples with very coarse texture $(n=5)$.

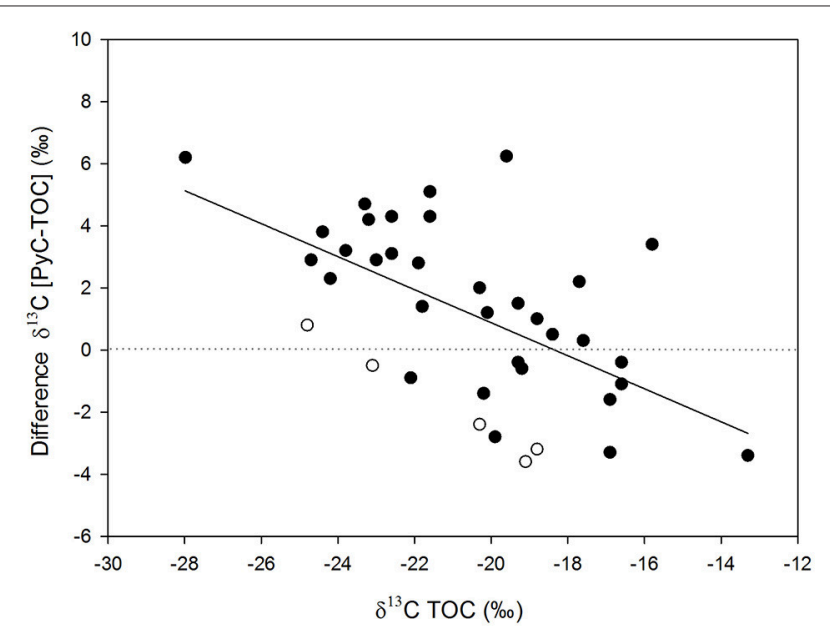

FIGURE 5 | Relationship between $\delta^{13} \mathrm{C}$ values of bulk sediment samples and differences in $\delta^{13} \mathrm{C}$ between the PyC component and the TOC pool; $r^{2} 0.34$; $p<0.05$. Open symbols correspond to samples with very coarse texture $(n=5)$.

pools in samples from more heavily wooded (wetter) savannas, while variations between size fractions were minimal in grassdominated environments (Figure 7). ANCOVA analyses showed that the regression obtained for the smallest fraction $(<10 \mu \mathrm{m})$ was significantly different to those obtained for larger fractions (Supplementary Table 1). Particle size fractions $>10 \mu \mathrm{m}$ had similar differences in $\delta^{13} \mathrm{C}$ values and comparable relative contributions of PyC to TOC $(P>0.05)$, while the finest fraction $(<10 \mu \mathrm{m})$ showed the largest differences in $\delta^{13} \mathrm{C}$ values between TOC and $\mathrm{PyC}$, and had the greatest relative contribution of $\mathrm{PyC}$ to TOC of the three size fractions considered (Figure 8). Differences in $\delta^{13} \mathrm{C}$ values and comparable relative contributions of PyC to TOC were significant $(P<0.05)$ between the $<10$ and $>125 \mu \mathrm{m}$ fractions.

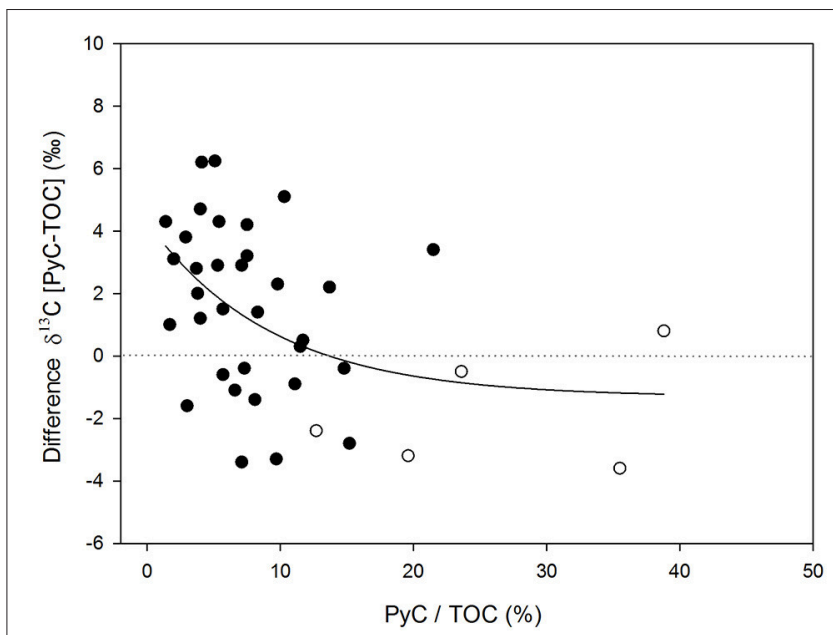

FIGURE 6 | Relationship between the relative contribution of PyC to TOC (\%) and differences in $\delta^{13} \mathrm{C}$ between the PyC component and the TOC pool; $r^{2} 0.19 ; p<0.05$. Open symbols correspond to samples with very coarse texture $(n=5)$.

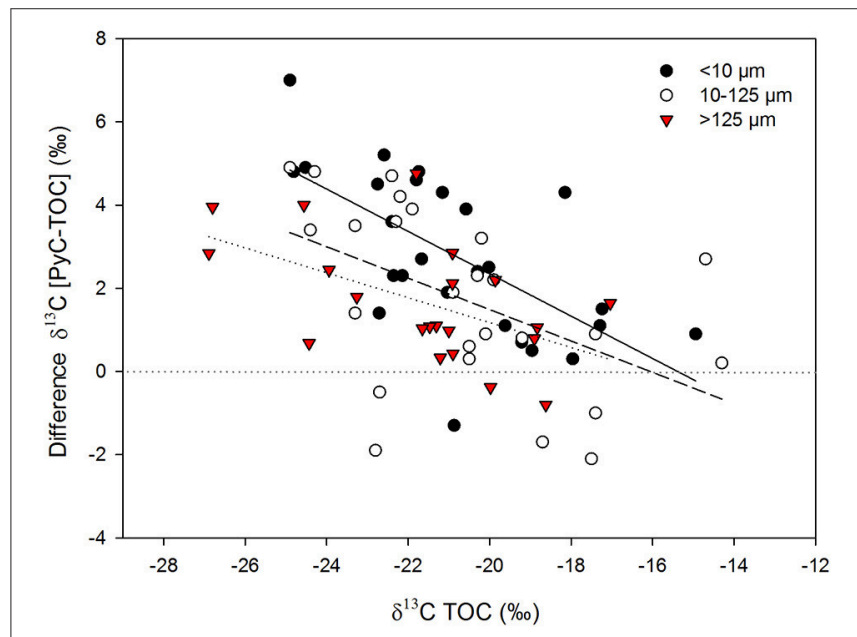

FIGURE 7 | Relationship between $\delta^{13} \mathrm{C}$ values of bulk sediment samples and differences in $\delta^{13} \mathrm{C}$ between the PyC component and the TOC pool for different size fractions; regression coefficients $\left(r^{2}\right)$ are 0.41 for the fractions < $10 \mu \mathrm{m}$ (solid line), 0.34 for the fractions between 10 and $125 \mu \mathrm{m}$ (dashed line), and 0.29 for the fractions $>125 \mu \mathrm{m}$ (dotted line); $p<0.05$ for all regressions.

\section{Relative Contribution of Size Fractions to Surface Carbon Pools in Fire Experiments}

Table 1 shows the relative contribution to TOC and $\mathrm{PyC}$ from different size fractions in vacuumed material from burnt and unburnt plots. There was a trend to increasing relative contributions with increasing particle size, with the largest fractions $(>125 \mu \mathrm{m})$ accounting for more than half of the total carbon in both the TOC and PyC pools. The smaller fractions showed a relative reduction in carbon contributions from burnt to unburnt plots, while the relative changes exhibited by the largest fraction were positive. 


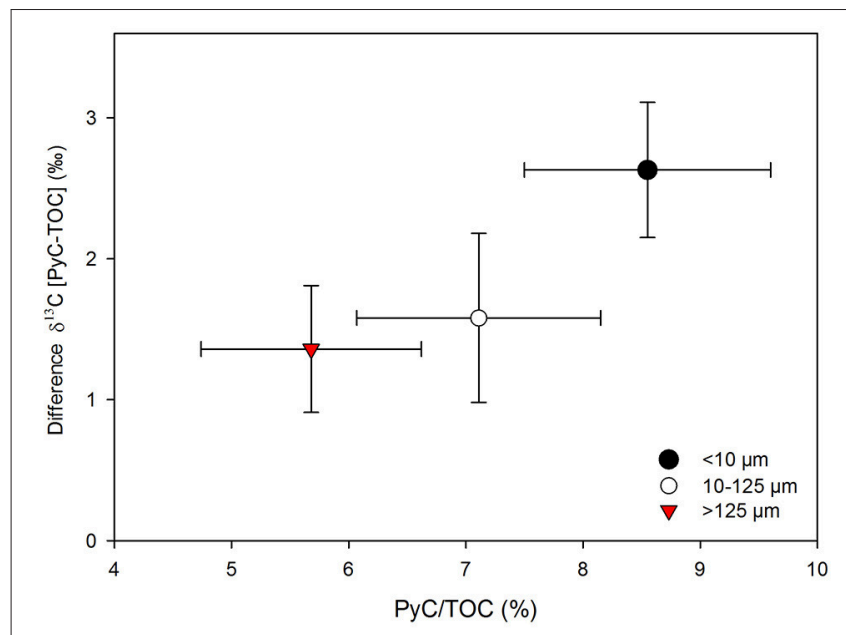

FIGURE 8 | Relationship between the relative contribution of PyC to TOC (\%) and differences in $\delta^{13} \mathrm{C}$ between the PyC component and the TOC pool for different size fractions $(n=23)$. Bars are standard errors of the means.

\section{DISCUSSION}

\section{Variation in the Geographical Distribution of PyC in Surface Sediments (Objective 1)}

This study focuses in particular on surficial sediments collected from farm dams in very small catchments. These locations were chosen as they collect erodible material that best reflects fresh organic matter $(\mathrm{OM})$ inputs and $\mathrm{PyC}$ produced by recent fires within each micro-basin. The variation in carbon content and stable isotopic composition of bulk sediment samples corresponded well with the gradual shift in vegetation along the transect (Figure 1). Figure 2 shows a consistent trend between the stable carbon isotope composition of sediment samples and two separate variables, each being a proxy for the proportions of $\mathrm{C}_{3}$ and $\mathrm{C}_{4}$ biomass in each micro-basin. The existence of these strong relationships provides additional confidence that the impact of algal and/or macrophyte carbon on the $\delta^{13} \mathrm{C}$ values of TOC is minimal. Distinctly lower $\delta^{13} \mathrm{C}$ values and higher TOC contents were observed in the more heavily wooded savannas occurring in the wetter northeastern end of the transect, in contrast to the higher ${ }^{13} \mathrm{C}$ values and generally lower TOC abundances of grass-dominated environments (Figure 3). This trend may be attributed to differences in the input rates and turnover times of grass and woody-derived carbon (Bird et al., 2000, 2004; Saiz et al., 2015b).

Besides environmental and biotic factors, the specific characteristics of the soil have also been shown to exert a strong influence on the potential preservation of OM (Saiz et al., 2012), and thus, may also represent a key factor affecting the relationship between $\delta^{13} \mathrm{C}$ and TOC in recent sediments. However, the degree of physical protection and chemical stabilization of OM that can be provided by the loose, recently eroded surface sediment, must be necessarily lower than that existing at deeper locations within the soil profile (Rumpel and Kögel-Knabner, 2011). We therefore suggest that the influence exerted by micro-basin soil characteristics on the relationship between $\delta^{13} \mathrm{C}$ and sediment TOC is of limited relevance in the present work, but cannot be entirely dismissed. In this regard, the impact of soil characteristics was particularly noticeable in very coarse-textured samples, which showed consistently low $\delta^{13} \mathrm{C}$ values of TOC values regardless of vegetation cover (Figure 3A).

While the relationship between $\delta^{13} \mathrm{C}$ values and TOC abundance showed a close parallel to the relationship between ${ }^{13} \mathrm{C}$ values and $\mathrm{PyC}$ content (Figures $3 \mathbf{A}, \mathbf{B}$ ), the relative contribution of $\mathrm{PyC}$ to TOC showed the opposite trend (Figure 3C). The contribution of $\mathrm{PyC}$ to TOC tended to be higher in grass-dominated savannas than in those dominated by woody vegetation, which supports our first hypothesis (H1) and the conclusion of Saiz et al. (2015a) that proportionally more recalcitrant PyC (HyPyC or SPAC) is produced per unit of TCE during combustion of grass-dominated savannas. The latter is the result of the incomplete combustion resultant from shortlived fires characteristic of these ecosystems. Moreover, work conducted along a precipitation gradient in West Africa reported higher contributions of resistant OC (inferred to be dominantly $\mathrm{PyC}$ ) to the total soil organic carbon (SOC) pool in low rainfall open-canopy savannas, with this attributed to the frequent fire events characteristic of those ecosystems (Saiz et al., 2012). It is worth noting that other fire-prone land cover types (e.g., forests) typically have longer fire return intervals, and also much higher TCE to fire. However, besides soils, the largest proportion of carbon stored in forest ecosystems is in tree stems, Though wildfires may combust whole trees, usually only a fraction of the TCE gets significantly affected or combust during forest fires (Santín et al., 2015), with leaves, twigs, barks, down wood, and forest floor being the fuels most commonly affected.

Nonetheless, frequent fires in a given ecosystem may not necessarily be always associated with high $\mathrm{PyC}$ contents above- or belowground, as this material undergoes a series of transformations (e.g., mineralization, infiltration, lateral translocation, etc.; Bird et al., 2015; Reisser et al., 2016), which will ultimately define the relative contribution of $\mathrm{PyC}$ to the TOC pool at a final location of deposition. In this regard, the characteristics of the soil also play an important role in modulating such contributions. Soils with low OC contents have shown to make relatively larger PyC contributions to total SOC than soils with higher OC contents (Reisser et al., 2016). Very coarse-textured materials have characteristically low nutrient levels, as well as limited water retention capacities (Schimel et al., 1994; Silver et al., 2000; Saiz et al., 2012), and the associated low net primary productivity may have contributed to the low TOC contents observed in some samples in the present study (Figures 3A, 4). Furthermore, the relatively high proportion of $\mathrm{PyC}$ in these sediments suggests the low degree of physicochemical protection that coarse-textured soils offer against $\mathrm{OM}$ decomposition, given that a significant proportion of the TOC corresponds to highly recalcitrant PyC material (i.e., HyPyC). Sediment samples containing over $20 \mathrm{mg} \mathrm{g}^{-1}$ TOC showed relatively uniform $\mathrm{PyC}$ contributions to TOC ( $\sim 7 \%$; Figure 4), broadly consistent with the global observations compiled by Reisser et al. (2016) for soil samples collected from the $0-30 \mathrm{~cm}$ depth interval. 
TABLE 1 | Relative contribution (\%) of different size fractions to both TOC and PyC in vacuumed material from recently burnt $(n=16)$ and unburnt $(n=32)$ vegetation quadrats.

\begin{tabular}{|c|c|c|c|c|c|c|}
\hline \multirow[t]{2}{*}{ Size fraction $(\mu \mathrm{m})$} & \multicolumn{3}{|c|}{ TOC } & \multicolumn{3}{|c|}{ PyC } \\
\hline & Burnt & Unburnt & Relative change (\%) & Burnt & Unburnt & Relative change (\%) \\
\hline$<10$ & $4.3 \pm 5.7$ & $1.4 \pm 0.5$ & -67 & $6.4 \pm 8.9$ & $2.5 \pm 2.0$ & -60 \\
\hline $10-125$ & $28.0 \pm 10.5$ & $15.8 \pm 8.1$ & -44 & $41.8 \pm 14.9$ & $23.8 \pm 11.7$ & -43 \\
\hline$>125$ & $67.7 \pm 10.9$ & $82.8 \pm 8.1$ & 22 & $51.8 \pm 14.4$ & $73.6 \pm 13.1$ & 42 \\
\hline
\end{tabular}

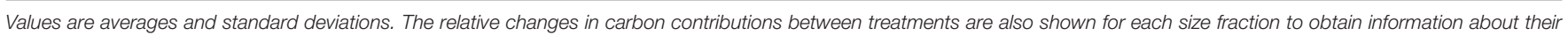

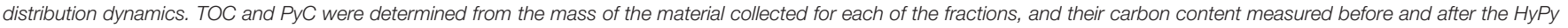
treatment. Unburnt quadrats had not experienced fire for at least two years.

Belowground OM inputs are directly subject to physicochemical protection offered by the soil matrix, but charcoal or PyC is overwhelmingly produced aboveground, and thus, is more prone to mineralization and/or transport from the site of production (Zimmermann et al., 2012; Bird et al., 2015). Rumpel et al. (2006) worked along the slopes of slash and burn agricultural land and noted that PyC from topsoil horizons was not primarily bound to mineral phases, which made it susceptible to translocation downslope. In the present study we made use of the relative changes in carbon contributions observed between burnt and unburnt treatments in 16 burning experiments to obtain information about the temporal evolution of TOC and $\mathrm{PyC}$ pools in three size fractions.

Earlier work by Saiz et al. (2015a) on the same experimental fires report an average $\mathrm{PyC}$ production of about $16 \%$ of all carbon being exposed, of which particles $>125 \mu \mathrm{m}$ represented more than $90 \%$ of the total mass. This particle size fraction has been shown to remain initially in the vicinity of the site of production (Clark, 1988; Saiz et al., 2015a), and was therefore classified as "proximal" PyC. Once produced, PyC remaining on the soil surface may subsequently (i) be re-combusted in future fires (Santín et al., 2013; Saiz et al., 2014) (ii) be re-mineralized by abiotic/biotic processes (Zimmerman, 2010; Zimmermann et al., 2012), (iii) accumulate in the SOC pool (Lehmann et al., 2008) and/or (iv) be re-mobilized by bioturbation, wind or water in either particulate (Rumpel et al., 2006; Major et al., 2010; Cotrufo et al., 2016) or dissolved form Dittmar et al. (2012). Table 1 reveals that proximal $\mathrm{PyC}$ contained in small-size fractions on the soil surface is gradually lost after a fire, thereby increasing the relative contribution of the largest size fraction to the total carbon pool over time. Therefore, comparatively finer material, such as that derived from grass biomass, would get more easily transported from the site of production, which is in support of the differential transport efficiencies between grass and woody fuels we hypothesized in $\mathrm{H} 2$ [see also section Preferential Transport of Grass-Derived PyC (Objective 3)]. Particle comminution makes it easier for proximal $\mathrm{PyC}$ to be exported from the site of production, and temporarily accumulate in lower locations within the landscape (e.g., farm dams). Small airborne particles exported during fire (i.e., distal PyC; Saiz et al., 2015a) may also contribute to the loading of $\mathrm{PyC}$ particles at these locations, although the reach of distal PyC may also be realized at regional and even much larger spatial scales (Kuhlbusch et al., 1996; Bird et al., 2015). Indeed, Duffin et al. (2008) suggested that in tropical savannas more than half of relatively small charcoal size $(<50 \mu \mathrm{m})$ is likely to be transported $>15 \mathrm{~km}$ from the fire line.

\section{Preferential Combustion of Grass Biomass and Factors Affecting the Isotopic Composition of PyC (Objective 2)}

Differences between the $\delta^{13} \mathrm{C}$ values of TOC and its $\mathrm{PyC}$ component in surface sediments sampled across a wide range of tropical savannas indicate that the $\delta^{13} \mathrm{C}$ value of $\mathrm{PyC}$ is partly decoupled from that of TOC and therefore of local biomass (Figure 5). This further supports previous conclusions that $\mathrm{HyPy}$ effectively isolates a distinct component of TOC (Wurster et al., 2012, 2013). While the carbon isotopic composition of PyC can provide very useful information of the type of vegetation being burnt in mixed $\mathrm{C}_{3} / \mathrm{C}_{4}$ ecosystems (Bird and Gröcke, 1997), there are several factors that need to be considered when interpreting these data. These include: (i) the physical fractionation of PyC particles derived from mixed $\mathrm{C}_{3} / \mathrm{C}_{4}$ vegetation due to preferential combustion of grasses in savannas (Furley et al., 2008; Saiz et al., 2015a), (ii) the savanna isotope disequilibrium effect (SIDE) that is the isotope fractionation accompanying the production of $\mathrm{PyC}$ during biomass combustion (Saiz et al., 2015a), (iii) the contrasting transport efficiencies, related to particle size differences, of particulate $\mathrm{PyC}$ derived from woody or grass sources (i.e., $\mathrm{C}_{3} / \mathrm{C}_{4}$ vegetation) (Clark, 1988; Duffin et al., 2008), and (iv) the specific characteristics of the topsoil where $\mathrm{PyC}$ is originally produced (Bird et al., 2000).

Analyses of the surficial sediment samples in this study indicate that the $\delta^{13} \mathrm{C}$ value of $\mathrm{PyC}$ is up to $7 \%$ higher than that of TOC, with these differences being largest when the $\delta^{13} \mathrm{C}$ values of TOC were low (i.e., characteristic of more wooded ecosystems; Figure 5). This suggests that a significant component of $\mathrm{C}_{4}$-derived $\mathrm{PyC}$ is present at most locations, even when the proportion of $\mathrm{C}_{4}$ biomass in the catchment is relatively small (Figure 1). Recent work employing carbon isotopic analyses in pools and fluxes of experimental fires conducted across mixed $\mathrm{C}_{3} / \mathrm{C}_{4}$ ecosystems shows that, compared to woody material, grass biomass is preferentially combusted (Saiz et al., 2015a), which would largely explain the presence of $\mathrm{C}_{4}$-derived $\mathrm{PyC}$ in woodland ecosystems. However, this mechanism cannot explain the observation that $\delta^{13} \mathrm{C}$ differences between TOC and $\mathrm{PyC}$ 
were smaller and even reversed in grass-dominated ecosystems (Figure 5).

The trends discussed above show the combined influence of some of the factors mentioned earlier. Firstly, the SIDE is more marked in grass-dominated ecosystems. Saiz et al. (2015a) showed that while the $\delta^{13} \mathrm{C}$ values of total $\mathrm{PyC}$ and $\mathrm{HyPyC}$ were generally lower by $1-3 \%$ compared to the original biomass across mixed $\mathrm{C}_{3} / \mathrm{C}_{4}$ savanna ecosystems, Mitchell grasslands-an ecosystem almost exclusively composed of $\mathrm{C}_{4}$ vegetation-showed strong ${ }^{13} \mathrm{C}$ depletion (up to 7\%) in recently produced total $\mathrm{PyC}$ and $\mathrm{HyPyC}$, resulting in comparatively larger SIDE values with the differences particularly pronounced in the fine size fractions. Secondly, the preferential export of fine particle size fractions during fire in grass-dominated ecosystems is likely to be dominated by low ${ }^{13} \mathrm{C}$ components (e.g., methoxyl-groups, lignins, phytoliths, etc.) preserved in PyC (O'Malley et al., 1997; Krull et al., 2003; Keppler et al., 2004; Das et al., 2010). Therefore, the comparatively smaller ${ }^{13} \mathrm{C}$ differences observed between TOC and PyC in grassdominated ecosystems may also be influenced by the superior transport efficiency of small particulate $\mathrm{PyC}$ derived from grass vegetation (Clark, 1988; H2). This latter aspect will be dealt with in more detail in the following section. Thirdly, the characteristics of the topsoil upon which $\mathrm{PyC}$ is produced may potentially affect carbon isotopic dynamics by means of differential physicochemical protection (Krull et al., 2003; Sollins et al., 2009; Zimmermann et al., 2012). In this regard, analyses of sediment samples show that ${ }^{13} \mathrm{C}$ values of $\mathrm{PyC}$ were consistently higher than those of TOC across a broad range of savanna sites occurring on coarse-textured soils (Figure 5).

The specific chemical, mineralogical, and textural properties of the topsoil may play a critical role on the preservation of OC (e.g., through the formation of aggregates, association with clay particles, etc.), and on its potential export (e.g., infiltration, erosion, etc.) (Brodowski et al., 2006; Knicker, 2011; Saiz et al., 2012; Singh et al., 2012). Hence, a limited physicochemical protection of OC would promote the preferential mineralization of labile compounds relative to more recalcitrant ones (e.g., $\mathrm{PyC})$. In the present study the low degree of physicochemical protection offered to TOC in coarse-textured soils is revealed by the greater relative contributions of $\mathrm{PyC}$ to TOC observed in those samples, which are also associated with larger positive differences in $\delta^{13} \mathrm{C}$ values between TOC and $\mathrm{PyC}$ (Figure 6).

Other potential fractionation processes occurring within the soil profile such as the microbial reprocessing of SOM or the differential stabilization of naturally heterogeneous SOM compounds (Bird et al., 1996; Ehleringer et al., 2000; Blagodatskaya et al., 2011; Rumpel and Kögel-Knabner, 2011) are of more limited significance in our work since we focus on very surficial sediments. Finally, differential mineralization patterns in $\mathrm{PyC}$ derived from different biomass sources (e.g., Saiz et al., 2015b) are not considered significant in this context given the very short timeframe since the PyC was produced.

\section{Preferential Transport of Grass-Derived PyC (Objective 3)}

Savanna fires preferentially burn the grass understory and surface litter rather than over-story trees (Furley et al., 2008), which may lead to a bias toward generally smaller $\mathrm{C}_{4}$-derived PyC. Several studies have demonstrated that charcoal in contrasting size fractions exhibit fundamentally different aerodynamic behaviors (Clark, 1988; Duffin et al., 2008). This behavior exerts a strong influence on their transport efficiencies whereby larger particles remain closer to their site of production than smaller particles. However, the preferential export of $\mathrm{PyC}$ is not only constrained to airborne particles produced during the fire. Indeed, $\mathrm{PyC}$ remaining close to the site of burning (proximal $\mathrm{PyC}$ ) will undergo continuous transformations after production. Table 1 demonstrates that both the abundance of TOC and $\mathrm{PyC}$ in smallsize surface material decrease over time after fire, which increases the relative contribution of larger particles to the total carbon pools at the site of burning. Because the stable components of PyC accrue both in situ and distally, the SIDE caused by fire produces soil or sedimentary records in savanna environments that are relatively ${ }^{13} \mathrm{C}$-depleted with respect to the original biomass (Wynn and Bird, 2008; Saiz et al., 2015a). This has significant implications for the interpretation of $\delta^{13} \mathrm{C}$ values of PyC preserved in the geological record, and for global ${ }^{13} \mathrm{C}$ isotopic disequilibria calculations needed in modeling studies that use variations in the $\mathrm{CO}_{2}{ }^{13} \mathrm{C}$ record to apportion sources and sinks of $\mathrm{CO}_{2}$ (Randerson et al., 2005; Saiz et al., 2015a).

The finest-most comminuted-size fraction $(<10 \mu \mathrm{m})$ consistently showed the largest differences in $\delta^{13} \mathrm{C}$ values between TOC and $\mathrm{PyC}$ along the transect (Figure 7), indicating that $\mathrm{C}_{4}$-derived $\mathrm{PyC}$ is more disproportionately represented in the finest size fraction. Moreover, the observed differences in $\delta^{13} \mathrm{C}$ values between size fractions decrease from the more wooded savannas to more grass-dominated savannas, with the resultant regressions being significantly different in the case of the smallest fraction (Figure 7, Supplementary Table 1). This can be explained by preferential transport of $\mathrm{PyC}$ generated from heterogeneous fuel sources. In savanna ecosystems, finer grass-derived $\mathrm{PyC}$ particles are preferentially exported from the site of initial production and accumulate in the sedimentary record, while the commonly larger $\mathrm{PyC}$ particles derived from the combustion of woody biomass $\left(\mathrm{C}_{3}\right)$ are more likely to remain closer to the site of burning (Saiz et al., 2015a). This differential particle transport efficiency will be more clearly reflected in the sedimentary record of more wooded savannas than in more grass-dominated savannas where the isotopic composition of the fuel source is much less heterogeneous. These results support our second hypothesis $(\mathrm{H} 2)$ that proposed that fine material produced during the combustion of grass-derived biomass may be preferentially exported from the site of production, with this being reflected in the preferential accumulation of $\mathrm{C}_{4}$ grassderived $\mathrm{PyC}$ in the sedimentary record, even in cases where the proportion of $\mathrm{C}_{4}$ grass biomass in the catchment was small.

While one of the main aims of this work is to infer a general pattern of PyC transportation across a broad gradient of tropical savannas, there are additional factors operating at a more local 
scale that may play a significant role in the spatial dynamics of $\mathrm{PyC}$ particle deposition and accumulation. In this regard, both the climatic and physical characteristics of the landscape may exert a strong influence in the erosional patterns of $\mathrm{PyC}$ (Rumpel et al., 2006, 2015; Cotrufo et al., 2016). Furthermore, the specific characteristics of the soil where $\mathrm{PyC}$ is produced may also have a strong impact on its transport and mineralization dynamics (e.g., contrasting PyC preservation in swelling and cracking Vertisols vs. loose sandy soils; Supplementary Table 2), which could ultimately affect both the abundance and carbon isotopic composition of $\mathrm{PyC}$ in the sedimentary record.

\section{Charcoal Particle Size Thresholds for Fire Research in Tropical Savannas (Objective 4)}

The particle size ranges adopted in this study were chosen to conform to standard dimensions adopted to classify microand macro-charcoal in palynological studies and in work assessing PyC production in tropical savannas (e.g., Blackford, 2000; Haberle, 2005; Saiz et al., 2015a). The significantly different behavior shown by the smallest particle size fraction $(<10 \mu \mathrm{m})$ in regards to: (i) the relative changes in carbon contributions between burnt and unburnt plots (Table 1), (ii) the differences in $\delta^{13} \mathrm{C}$ values between TOC and PyC across the vegetation transect (Figure 7), and (iii) the relative contribution of $\mathrm{PyC}$ to TOC (Figure 8), demonstrate that $\mathrm{PyC}$ of this size exhibits a substantially different behavior compared to $\mathrm{PyC}$ in the coarser fractions. This supports findings from previous research concluding that contrasting particle sizes of charcoal have different aerodynamic behaviors (Clark, 1988; Duffin et al., 2008), and further support the hypothesis (H2) that coarser charcoal fragments derived from combustion of woody sources accumulate close to the site of production.

Our results agree well with the statement by Duffin et al. (2008) about the need to use just a few size classes of charcoal in the sedimentary record of savanna environments to obtain relevant information on fire proximity and relevant source areas of pyrogenic material. These authors advocate the use of a $50 \mu \mathrm{m}$ threshold for savannas as they identified a differential behavior of charcoal particles up to and beyond that fraction size. Such a threshold seems plausible in view of our own results, as the intermediate particle size range considered in the present study show mixed patterns between the smallest $(<10 \mu \mathrm{m})$ and largest $(>125 \mu \mathrm{m})$ fractions (Figure 8).

\section{CONCLUSIONS}

We used HyPy to obtain robust estimates of $\mathrm{PyC}$ abundance and stable isotope composition in surface sediments in small dams across a broad range of mixed $\mathrm{C}_{3} / \mathrm{C}_{4}$ tropical vegetation. Our study shows that the contribution of highly recalcitrant $\mathrm{PyC}$ to TOC in grass-dominated savannas tends to be higher than in savannas where woody vegetation was more prominent. This is partly because fires characteristic of grass-dominated savannas significantly affect, if not all, most of the TCE. However, the short-lived nature of these fires may cause an incomplete combustion of the fuels, which results in the production of proportionately more recalcitrant $\mathrm{PyC}(\mathrm{HyPyC})$ per unit of TCE than that observed in woodier savannas (Saiz et al., 2015a).

This work also provides evidence for the preferential combustion of grass biomass and higher transport efficiency of $\mathrm{C}_{4}$-derived $\mathrm{PyC}$ in mixed ecosystems where grass and woody vegetation coexist. In savanna ecosystems finer grass-derived PyC particles are preferentially exported and accumulated in sediments, while the commonly larger $\mathrm{PyC}$ particles derived from the combustion of woody biomass $\left(\mathrm{C}_{3}\right)$ are more likely to remain closer to the site of burning. We demonstrate that after a fire there is a comminution of $\mathrm{PyC}$ produced in-situ to smaller particles, which then facilitates transport away from the site of production and may also affect the preservation potential of this material. Our isotopic approach provides independent validation of findings by Duffin et al. (2008) concerning the appropriateness of adopting a relatively small particle size threshold (i.e., $\sim 50 \mu \mathrm{m}$ ) to reconstruct fire regimes using sedimentary records by conventional charcoal counting techniques.

While the isotopic composition of $\mathrm{PyC}$ contained in sediment records can greatly assist in reconstructing past fire regimes, this study suggests that there are several factors that need to be considered when interpreting these data. These include the physical fractionation and contrasting transport efficiencies of PyC particles derived from mixed $\mathrm{C}_{3} / \mathrm{C}_{4}$ sources, the savanna isotope disequilibrium effect accompanying the production of $\mathrm{PyC}$ during biomass combustion, and the specific characteristics of the topsoil where $\mathrm{PyC}$ is originally produced. Our work also allows for a more nuanced understanding of the savanna isotope disequilibrium effect, which has significant implications for global ${ }^{13} \mathrm{C}$ isotopic disequilibria calculations and for the interpretation of $\delta^{13} \mathrm{C}$ values of PyC preserved in sedimentary records (Saiz et al., 2015a). While we have conducted this study in tropical savannas, we believe it is highly likely that the findings of this study can directly apply to savannas in temperate environments.

We suggest that the combined use of an isotopic approach and classical research methods exploiting the sedimentary record, including charcoal counting and the interpretations of charcoal morphotypes, appears to be particularly suitable for use in mixed fuel source fire regimes (Leys et al., 2015, 2017). This combined approach will allow for more accurate reconstructions of past fire regimes and promote a better understanding of PyC dynamics in tropical savannas. This research further demonstrates that the HyPy technique enables an accurate quantification of an essential component of terrestrial carbon, and that it is a very useful tool for promoting a better understanding of the dynamic role of biomass burning in the global carbon cycle.

\section{AUTHOR CONTRIBUTIONS}

GS, IG, and MB designed the experiment. GS, IG, and CW carried out the fieldwork and conducted laboratory analyses. GS wrote the manuscript with contributions from all co-authors. 


\section{FUNDING}

This work was supported by Australia Research Council Grants DP1096586 and FF0883221.

\section{ACKNOWLEDGMENTS}

We are indebted to the many generous individuals who granted us access to their farms. We gratefully acknowledge Queensland Parks and Wildlife staff, and particularly Rob Miller, for access to

\section{REFERENCES}

Andela, N., Morton, D. C., Giglio, L., Chen, Y., van der Werf, G. R., Kasibhatla, P. S., et al. (2017). A human-driven decline in global burned area. Science 356, 1356-1362. doi: 10.1126/science.aal4108

Andreae, M. O., and Merlet, P. (2001). Emission of trace gases and aerosols from biomass burning. Global Biogeochem. Cycles 15, 955-966. doi: 10.1029/2000GB001382

Bird, M. I., Chivas, A. R., and Head, J. (1996). A latitudinal gradient in carbon turnover times in forest soils. Nature 381, 143-146. doi: 10.1038/381143a0

Bird, M. I., and Gröcke, D. R. (1997). Determination of the abundance and carbon isotope composition of elemental carbon in sediments. Geochim. Cosmochim. Acta 61, 3413-3423. doi: 10.1016/S0016-7037(97)00157-9

Bird, M. I., Veenendaal, E. M., and Lloyd, J. J. (2004). Soil carbon inventories and $\delta^{13} \mathrm{C}$ along a moisture gradient in Botswana. Global Change Biol. 10, 342-349. doi: 10.1046/j.1365-2486.2003.00695.x

Bird, M. I., Veenendaal, E. M., Moyo, C., Lloyd, J., and Frost, P. (2000). Effect of fire and soil texture on soil carbon in a sub-humid savanna (Matopos, Zimbabwe). Geoderma 94, 71-90. doi: 10.1016/S0016-7061(99)00084-1

Bird, M., Wynn, J. G., Saiz, G., Wurster, C. M., and McBeath, A. (2015). The Pyrogenic Carbon Cycle. Annu. Rev. Earth Planet. Sci. 43, 273-298. doi: 10.1146/annurev-earth-060614-105038

Blackford, J. J. (2000). Charcoal fragments in surface samples following a fire and the implications for interpretation of subfossil charcoal data. Palaeogeogr. Palaeoclimatol. Palaeoecol. 164, 33-42. doi: 10.1016/S0031-0182(00)00173-5

Blagodatskaya, E., Yuyukina, T., Blagodatsky, S., and Kuzyakov, Y. (2011). Turnover of soil organic matter and of microbial biomass under $\mathrm{C}_{3}-\mathrm{C}_{4}$ vegetation change: consideration of ${ }^{13} \mathrm{C}$ fractionation and preferential substrate utilization. Soil Biol. Biochem. 43, 159-166. doi: 10.1016/j.soilbio.2010.09.028

Brodowski, S., John, B., Flessa, H., and Amelung, W. (2006). Aggregateoccluded black carbon in soil. Eur. J. Soil Sci. 57, 539-546. doi: $10.1111 / j .1365-2389.2006 .00807 . x$

Clark, J. S. (1988). Particle motion and the theory of charcoal analysis: source area, transport, deposition, and sampling. Quat. Res. 30, 67-80. doi: 10.1016/0033-5894(88)90088-9

Conedera, M., Tinner, W., Neff, C., Meurer, M., Dickens, A. F., and Krebs, P. (2009). Reconstructing past fire regimes: methods, applications, and relevance to fire management and conservation. Quat. Sci. Rev. 28, 555-576. doi: 10.1016/j.quascirev.2008.11.005

Cotrufo, M. F., Boot, C., Abiven, S., Foster, E. J., Haddix, M., Reisser, M., et al. (2016). Quantification of pyrogenic carbon in the environment: an integration of analytical approaches. Org. Geochem. 100, 42-50. doi: 10.1016/j.orggeochem.2016.07.007

Crawford, A. J., and C. M., Belcher (2014). Charcoal morphometry for paleoecological analysis: the effects of fuel type and transportation on morphological parameters. Appl. Plant Sci. 2:1400004. doi: 10.3732/apps.1400004

Das, O., Wang, Y., and Hsieh, Y.-P. (2010). Chemical and carbon isotopic characteristics of ash and smoke derived from burning of $\mathrm{C} 3$ and $\mathrm{C} 4$ grasses. Org. Geochem. 41, 263-269. doi: 10.1016/j.orggeochem.2009.11.001

Dittmar, T., De Rezende, C. E., Manecki, M., Niggemann, J., Ovalle, A. R. C., Stubbins, A., et al. (2012). Continuous flux of dissolved black carbon from a vanished tropical forest biome. Nat. Geosci. 5, 618-622. doi: 10.1038/ngeo1541 sites at Undara and Davies Creek. We also thank Sandra Lopez for her continuous support in this study. We are also thankful to the Australian Wildlife Conservancy Society for allowing access and permits to undertake research at the Brooklyn Sanctuary site.

\section{SUPPLEMENTARY MATERIAL}

The Supplementary Material for this article can be found online at: https://www.frontiersin.org/articles/10.3389/feart. 2017.00115/full\#supplementary-material

Duffin, K. I., Gillson, L., and Willis, K. J. (2008). Testing the sensitivity of charcoal as an indicator of fire events in savanna environments: quantitative predictions of fire proximity, area and intensity. Holocene 18, 279-291. doi: 10.1177/0959683607086766

Ehleringer, J. R., Buchmann, N., and Flanagan, L. B. (2000). Carbon isotope ratios in belowground carbon cycle processes. Ecol. Appl. 10, 412-422. doi: 10.1890/ 1051-0761(2000)010[0412:CIRIBC]2.0.CO;2

Furley, P. A., Rees, R. M., Ryan, C. M., and Saiz, G. (2008). Savanna burning and the assessment of long-term fire experiments with particular reference to Zimbabwe. Prog. Phys. 32, 611-634. doi: 10.1177/0309133308101383

Giglio, L., Randerson, J. T., and Werf, G. R. (2013). Analysis of daily, monthly, and annual burned area using the fourth-generation global fire emissions database (GFED4). J. Geophys. Res. Biogeosci. 118, 317-328. doi: 10.1002/jgrg.20042

Haberle, S. G. (2005). A 23,000-yr pollen record from Lake Euramoo, wet tropics of NE Queensland, Australia. Quat. Res. 64, 343-356. doi: 10.1016/j.yqres.2005.08.013

Karfs, R., Daly, C., Beutel, T., Peel, L., and Wallace J. F., (2004). "VegMachineDelivering monitoring information to northern Australia's pastoral industry," in Proceedings of the 12th Australasian Remote Sensing and Photogrammetry Conference' (Deakin, ACT: Spatial Sciences Institute).

Keppler, F., Kalin, R. M., Harper, D. B., McRoberts, W. C., and Hamilton, J. (2004). Carbon isotope anomaly in the major plant C 1 pool and its global biogeochemical implications. Biogeosciences 1, 123-131. doi: 10.5194/bg-1-123-2004

Knicker, H. (2011). Pyrogenic organic matter in soil: its origin and occurrence, its chemistry and survival in soil environments. Quat. Int. 243, 251-263. doi: 10.1016/j.quaint.2011.02.037

Krull, E., Skjemstad, J., Graetz, D., Grice, K., Dunning, W., Cook, G., et al. (2003). $\mathrm{C}$-13-depleted charcoal from $\mathrm{C} 4$ grasses and the role of occluded carbon in phytoliths. Org. Geochem. 34, 1337-1352. doi: 10.1016/S0146-6380(03)00100-1

Kuhlbusch, T., Andreae, M. O., Cachier, H., Goldammer, J. G., Lacaux, J. P., Shea, R., et al. (1996). Black carbon formation by savanna fires: measurements and implications for the global carbon cycle. J. Geophys. Res. Atmos. 101, 23651-23665. doi: 10.1029/95JD02199

Lehmann, J., Skjemstad, J., Sohi, S., Carter, J., Barson, M., Falloon, P., et al. (2008). Australian climate-carbon cycle feedback reduced by soil black carbon. Nat. Geosci. 1, 832-835. doi: 10.1038/ngeo358

Leys, B. A., Brewer, S. C., McConaghy, S., Mueller, J., and McLauchlan, K. K. (2015). Fire history reconstruction in grassland ecosystems: amount of charcoal reflects local area burned. Environ. Res. Lett. 10:114009. doi: 10.1088/1748-9326/10/11/114009

Leys, B. A., Commerford, J. L., and McLauchlan, K. K. (2017). Reconstructing grassland fire history using sedimentary charcoal: considering count, size and shape. PLoS ONE 12:e0176445. doi: 10.1371/journal.pone.0176445

Major, J., Lehmann, J., Rondon, M., and Goodale, C. (2010). Fate of soil-applied black carbon: downward migration, leaching and soil respiration. Global Change Biol. 16, 1366-1379. doi: 10.1111/j.1365-2486.2009.02044.x

Marlon, J. R., Kelly, R., Daniau, A.-L., Vannière, B., Power, M. J., Bartlein, P., et al. (2016). Reconstructions of biomass burning from sediment charcoal records to improve data-model comparisons. Biogeosciences 13, 3225-3244. doi: 10.5194/bg-13-3225-2016

Mastrolonardo, G., Hudspith, V. A., Francioso, O., Rumpel, C., Montecchio, D., Doerr, S. H., et al. (2017). Size fractionation as a tool for separating charcoal 
of different fuel source and recalcitrance in the wildfire ash layer. Sci. Total Environ. 595, 461-471. doi: 10.1016/j.scitotenv.2017.03.295

Meredith, W., Ascough, P. L., Bird, M. I., Large, D. J., Snape, C. E., Sun, Y., et al. (2012). Assessment of hydropyrolysis as a method for the quantification of black carbon using standard reference materials. Geochim. Cosmochim. Acta 97, 131-147. doi: 10.1016/j.gca.2012.08.037

Millspaugh, S. H., and Whitlock, C. (1995). A 750-year fire history based on lake sediment records in central Yellowstone National Park, USA. Holocene 5, 283-292. doi: 10.1177/095968369500500303

O'Malley, V. P., Burke, R. A., and Schlotzhauer, W. S. (1997). Using GC-MS/Combustion/IRMS to determine the ${ }^{13} \mathrm{C} /{ }^{12} \mathrm{C}$ ratios of individual hydrocarbons produced from the combustion of biomass materials-application to biomass burning. Org. Geochem. 27, 567-581. doi: 10.1016/S0146-6380(97)00087-9

Patterson, W. A., Edwards, K. J., and Maguire, D. J. (1987). Microscopic charcoal as a fossil indicator of fire. Quat. Sci. Rev. 6, 3-23. doi: 10.1016/0277-3791(87)90012-6

Randerson, J. T., Van der Werf, G. R., Collatz, G. J., Giglio, L., Still, C. J., Kasibhatla, P., et al. (2005). Fire emissions from $C_{3}$ and $C_{4}$ vegetation and their influence on interannual variability of atmospheric $\mathrm{CO}_{2}$ and ${ }^{13} \mathrm{CO}_{2}$. Global Biogeochem. Cycles 19, GB2019. doi: 10.1029/2004GB002366

Reisser, M., Purves, R., Schmidt, M. W., and Abiven, S. (2016). Pyrogenic Carbon in soils: a literature-based inventory and a global estimation of its content in soil organic carbon and stocks. Front. Earth Sci. 4:80. doi: 10.3389/feart.2016. 00080

Rumpel, C., Alexis, M., Chabbi, A., Chaplot, V., Rasse, D. P., Valentin, C., et al. (2006). Black carbon contribution to soil organic matter composition in tropical sloping land under slash and burn agriculture. Geoderma 130, 35-46. doi: 10.1016/j.geoderma.2005.01.007

Rumpel, C., and Kögel-Knabner, I. (2011). Deep soil organic matter-a key but poorly understood component of terrestrial C cycle. Plant Soil 338, 143-158. doi: 10.1007/s11104-010-0391-5

Rumpel, C., Leifeld, J., Santin, C., and Doerr, S. (2015). "Movement of biochar in the environment," in Biochar for Environmental Management: Science, Technology and Implementation, eds J. Lehmann and S. Joseph (Abingdon: Routledge), 283-300.

Saiz, G., Bird, M. I., Domingues, T., Schrodt, F., Schwarz, M., Feldpausch, T. R., et al. (2012). Variation in soil carbon stocks and their determinants across a precipitation gradient in West Africa. Global Change Biol. 18, 1670-1683. doi: $10.1111 / j .1365-2486.2012 .02657 . x$

Saiz, G., Wynn, J. G., Wurster, C. M., Goodrick, I., Nelson, P. N., and Bird, M. I. (2015a). Pyrogenic carbon from tropical savanna burning: production and stable isotope composition. Biogeosciences 12, 1849-1863. doi: 10.5194/bg-12-1849-2015

Saiz, G., Bird, M., Wurster, C., Quesada, C. A., Ascough, P., Domingues, T., et al. (2015b). The influence of $\mathrm{C}_{3}$ and $\mathrm{C}_{4}$ vegetation on soil organic matter dynamics in contrasting semi-natural tropical ecosystems. Biogeosciences 12, 5041-5059. doi: 10.5194/bg-12-5041-2015

Saiz, G., Goodrick, I., Wurster, C. M., Zimmermann, M., Nelson, P. N., and Bird, M. I. (2014). Charcoal re-combustion efficiency in tropical savannas. Geoderma 219, 40-45. doi: 10.1016/j.geoderma.2013.12.019

Santín, C., and Doerr, S. H. (2016). Fire effects on soils: the human dimension. Philos. Trans. R. Soc. Lond. B Biol. Sci. 371:20150171. doi: 10.1098/rstb.2015.0171

Santín, C., Doerr, S. H., Preston, C., and Bryant, R. (2013). Consumption of residual pyrogenic carbon by wildfire. Int. J. Wildland Fire 22, 1072-1077. doi: 10.1071/WF12190

Santín, C., Doerr, S. H., Preston, C., and González-Rodríguez, G. (2015). Pyrogenic organic matter production from wildfires: a missing sink in the global carbon cycle. Glob. Chang. Biol. 21, 1621-1633. doi: 10.1111/gcb. 12800
Schimel, D. D., Braswell, B. H., Holland, E. E., McKeown, R., Ojima, D. S. Painter, T. H., et al. (1994). Climatic, Edaphic, and Biotic controls over storage and turnover of carbon in soils. Global Biogeochem. Cycles 8, 279-293. doi: 10.1029/94GB00993

Silver, W., Neff, J., McGroddy, M., Veldkamp, E., Keller, M., and Cosme, R. (2000). Effects of soil texture on belowground carbon and nutrient storage in a lowland Amazonian forest ecosystem. Ecosystems 3, 193-209. doi: $10.1007 /$ s100210000019

Singh, N., Abiven, S., Torn, M. S., and Schmidt, M. W. I. (2012). Fire-derived organic carbon in soil turns over on a centennial scale. Biogeosciences 9, 2847-2857. doi: 10.5194/bg-9-2847-2012

Sollins, P., Kramer, M. G., Swanston, C., Lajtha, K., Filley, T., Aufdenkampe, A. K., et al. (2009). Sequential density fractionation across soils of contrasting mineralogy: evidence for both microbial-and mineralcontrolled soil organic matter stabilization. Biogeochemistry 96, 209-231. doi: 10.1007/s10533-009-9359-z

Thevenon, F., Williamson, D., Bard, E., Anselmetti, F. S., Beaufort, L., and Cachier, H. (2010). Combining charcoal and elemental black carbon analysis in sedimentary archives: implications for past fire regimes, the pyrogenic carbon cycle, and the human-climate interactions. Glob. Planet. Change 72, 381-389. doi: 10.1016/j.gloplacha.2010.01.014

Thevenon, F., Williamson, D., Vincens, A., Taieb, M., Merdaci, O., Decobert, M., et al. (2003). A late-Holocene charcoal record from Lake Masoko, SW Tanzania: climatic and anthropologic implications. Holocene 13, 785-792. doi: 10.1191/0959683603hl665rr

Torello-Raventos, M., Feldpausch, T. R., Veenendaal, E., Schrodt, F., Saiz, G., Domingues, T. F., et al. (2013). On the delineation of tropical vegetation types with an emphasis on forest/savanna transitions. Plant Ecol. Divers. 6, 101-137. doi: 10.1080/17550874.2012.762812

Wurster, C. M. C., Lloyd, J. J., Goodrick, I. I., Saiz, G. G., and Bird, M. I. M. (2012). Quantifying the abundance and stable isotope composition of pyrogenic carbon using hydrogen pyrolysis. Rapid Commun. Mass Spectrom. 26, 2690-2696. doi: $10.1002 / \mathrm{rcm} .6397$

Wurster, C. M., Saiz, G., Schneider, M. P., Schmidt, M. W., and Bird, M. I. (2013). Quantifying pyrogenic carbon from thermosequences of wood and grass using hydrogen pyrolysis. Org. Geochem. 62, 28-32. doi: 10.1016/j.orggeochem.2013.06.009

Wynn, J. G., and Bird, M. I. (2008). Environmental controls on the stable carbon isotopic composition of soil organic carbon: implications for modelling the distribution of $\mathrm{C}_{3}$ and $\mathrm{C}_{4}$ plants, Australia. Tellus B 60, 604-621. doi: 10.1111/j.1600-0889.2008.00361.x

Zimmerman, A. R. (2010). Abiotic and microbial oxidation of laboratoryproduced black carbon (biochar). Environ. Sci. Technol. 44, 1295-1301. doi: $10.1021 /$ es 903140 c

Zimmermann, M., Bird, M. I., Wurster, C., Saiz, G., Goodrick, I., Barta, J., et al. (2012). Rapid degradation of pyrogenic carbon. Global Change Biol. 18, 3306-3316. doi: 10.1111/j.1365-2486.2012.02796.x

Conflict of Interest Statement: The authors declare that the research was conducted in the absence of any commercial or financial relationships that could be construed as a potential conflict of interest.

The reviewer SD, and handling Editor declared their shared affiliation.

Copyright (๑) 2018 Saiz, Goodrick, Wurster, Nelson, Wynn and Bird. This is an open-access article distributed under the terms of the Creative Commons Attribution License (CC BY). The use, distribution or reproduction in other forums is permitted, provided the original author(s) or licensor are credited and that the original publication in this journal is cited, in accordance with accepted academic practice. No use, distribution or reproduction is permitted which does not comply with these terms. 